\title{
Efficacy of platelet-rich plasma injection in mild and moderate carpal tunnel syndrome: randomized control study
}

\author{
Souzan E. Gado* and Hanaa S. EL-Banna
}

\begin{abstract}
Background: Carpal tunnel syndrome (CTS) is the most common peripheral entrapment neuropathy. Typical symptoms and signs include numbness, tingling, pain, or burning sensation in the digits supplied by the median nerve and/or nocturnal paresthesia. Treatments of CTS range from conservative measures to surgical decompression of the median nerve.

Results: The PRP group showed a statistically significant reduction in the visual analog scale, Boston Carpal Tunnel Syndrome Questionnaire, for the severity and the functional capacity scores, and cross-sectional area of the median nerve compared to those of control group 3 months post-treatment $(p<0.05)$.

Conclusions: Platelet-rich plasma injection in CTS relieves pain and symptom severity and improves functional status but not significantly improve the electrophysiological parameters.
\end{abstract}

Keywords: Carpal tunnel syndrome, Platelet rich plasma

\section{Background}

Carpal tunnel syndrome (CTS) is the most common peripheral entrapment neuropathy [1]. Treatments of CTS range from conservative measures, such as non-steroidal anti-inflammatory drugs (NSAIDs), wrist splints, corticosteroids injection, local injection of insulin [2], or physical therapy to surgical decompression of the median nerve $[3,4]$.

Surgical intervention is considered by some authors more effective than conservative treatment for CTS [5]. However, conservative therapies are more suitable for mild to moderate cases [6]. Despite the availability of multiple conservative therapies for CTS, their efficacy is usually unfavorable or not sufficient [7]. So, it is important to develop novel therapeutic interventions for CTS.

Platelet-rich plasma (PRP) is a biologic product of concentrated platelets; it contains several growth factors well known to be effective on inflammation and wound

\footnotetext{
*Correspondence: souzan.gado@med.tanta.edu.eg

Department of Rheumatology, Physical Medicine \& Rehabilitation, Faculty of Medicine, Tanta University, Elgeish St., Tanta, Gharbia, Egypt
}

healing. These factors include transforming growth factor (TGF), vascular endothelial growth factor (VEGF), platelet-derived growth factor (PDGF), epidermal growth factor (EGF), and the insulin-like growth factor-1 (IGF-1) [8, 9].

PRP was recently shown to possibly promote axon regeneration and neurological recovery. It has also been shown to have acceptable success rates in treatment of clinical peripheral neuropathies $[10,11]$.

Regenerative medicine techniques, which involve regenerating human cells, tissues, or organs to restore normal function, have been increasingly used in the treatment of various musculoskeletal disorders. In this regard, dextrose and platelet-rich plasma (PRP) are the two most commonly used regenerative injection regimens, and numerous in vitro and in vivo studies have shown their potential role in promoting tissue repair. Furthermore, the pathophysiology of CTS comprises increased intra-compartment pressure and microcirculatory disturbance in subsynovial connective tissue [12-14].

\section{Springer Open}

(๑) The Author(s). 2020 Open Access This article is licensed under a Creative Commons Attribution 4.0 International License, which permits use, sharing, adaptation, distribution and reproduction in any medium or format, as long as you give appropriate credit to the original author(s) and the source, provide a link to the Creative Commons licence, and indicate if changes were made. The images or other third party material in this article are included in the article's Creative Commons licence, unless indicated otherwise in a credit line to the material. If material is not included in the article's Creative Commons licence and your intended use is not permitted by statutory regulation or exceeds the permitted use, you will need to obtain permission directly from the copyright holder. To view a copy of this licence, visit http://creativecommons.org/licenses/by/4.0/. 
A cadaveric study has demonstrated that a bolus saline injection could electively reduce the peak gliding resistance of the median nerve. Another randomized controlled trial pointed out that precise hydro-dissection of the median nerve using saline under ultrasound guidance yielded better clinical outcomes than subcutaneous saline injection. Therefore, the observed superiority of D5W over PRP (with respect to CTS symptoms) in this meta-analysis may be partly derived from a higher injection volume and the mechanical effect of nerve hydrodissection guided by ultrasound imaging $[15,16]$.

\section{Methods}

\section{Inclusion criteria}

Patients with confirmed clinical diagnosis (paresthesia of the hand exacerbated by repetitive use or sleep and improved by shaking the hand, numbness in the radial $31 / 2$ digits and motor weakness of thenar muscles, positive Phalen's test and/or Tinel's sign) and electrophysiological diagnosis of mild and moderate CTS were included.

CTS severity was categorized by the electrophysiological classification of CTS by Padua et al. [17] as follows: mild, only abnormal sensory nerve conduction velocity (SNCV) with normal distal motor latency of the median nerve (DML); moderate, abnormal SNCV and abnormal DML; or severe, absence of SNCV and abnormal DML.

\section{Exclusion criteria}

Patients with history of previous carpal tunnel release surgery, previous steroid injection for carpal tunnel syndrome in the past 3 months, polyneuropathy, brachial plexopathy, or thoracic outlet syndrome, pregnancy, bilateral CTS, or atrophy of thenar muscles and patients with PRP contraindications including history of malignancies, autoimmune disorders, thrombocytopenia, platelet dysfunction, or systemic infection were excluded.

\section{Study design}

This study included 40 patients with unilateral mild to moderate CTS selected from the Outpatient Clinic of Physical Medicine, Rheumatology and Rehabilitation Department, University Hospitals, during 2019. The selected patients were randomly categorized into two groups (envelop randomization).

The control group and PRP group used a prefabricated wrist splint at neutral position and they were instructed to put on the splint overnight for $8 \mathrm{~h}$ daily.

The PRP group also received a single ultrasoundguided injection of $3 \mathrm{~mL}$ of PRP processed using the Rooyagen kit (made by Arya Mabna Tashkis Corporation, RN: 312,569).

\section{Leucocytes poor PRP preparation}

Ten milliliters of blood were drawn from the patient's antecubital vein using an 18-G needle, then $1 \mathrm{~mL}$ of acid-citrate-dextrose was added to the blood sample as an anticoagulant and passed two stages of centrifugation, first at $1600 \mathrm{rpm}$ for $12 \mathrm{~min}$ to separate the erythrocytes and then at $3500 \mathrm{rpm}$ for $7 \mathrm{~min}$ in order to concentrate the platelets $[18,19]$.

\section{Ultrasound-guided injection}

The ultrasound-guided PRP injection was performed in the Ultrasound Unit of the Rheumatology Department, University Hospitals (SAMSUNG MEDISON, UGEO $\mathrm{H60}$ ), with linear array transducers (with frequencies ranging between 7.5 and $12 \mathrm{MHz}$ ) by a rheumatologist experienced in MSUS imaging. The patient's hand was comfortably rested on a pillow placed over the thighs, with the palm upwards and the wrist slightly extended; the median nerve $(\mathrm{MN})$ was identified at the inlet of the proximal carpal tunnel at the pisiform bone [20]. The ultrasound-guided injection was done using the in-plane ulnar approach [21]; the needle was passed from the ulnar side of the wrist toward the $\mathrm{MN}$, avoiding the ulnar artery identified by Doppler signals. Two milliliters of PRP was injected to peel the nerve off the flexor retinaculum via hydrodissection. The residual $1 \mathrm{~mL}$ of PRP was applied to the inferior part of the MN. The carpal tunnel was scanned to ensure that the PRP reached to the distal area of the carpal tunnel (Fig. 1). All patients were observed for $10 \mathrm{~min}$ after injection for pain, pruritus, or bleeding and instructed about activity restrictions by using wrist splints and icing on the injection site.

All patients of both groups were assessed before intervention and at 1 and 3 months after treatment by the following:

- Visual analog scale (VAS) [22]: the pain severity was determined on a scale from 0 (no pain) to 10 (agonizing pain).

- The Boston Carpal Tunnel Syndrome Questionnaire (BCTQ) [23] was used for evaluating the severity of symptoms and functional status of patients. The symptom severity scale consists of 11 questions, and the scores range from 1 to 5 . The functional status scale consists of 8 questions, and the scores range from 1 to 5 points; higher scores mean worse severity and dysfunction.

- Cross-sectional area (CSA) of MN: CSA was measured at the proximal inlet of the carpal tunnel using the pisiform bone as a landmark (Fig. 2). The average of CSA was randomly calculated. Inter-rater reliability: all images were read independently by two observers blinded to clinical and electrophysiological findings. Two images for each patient were performed. 


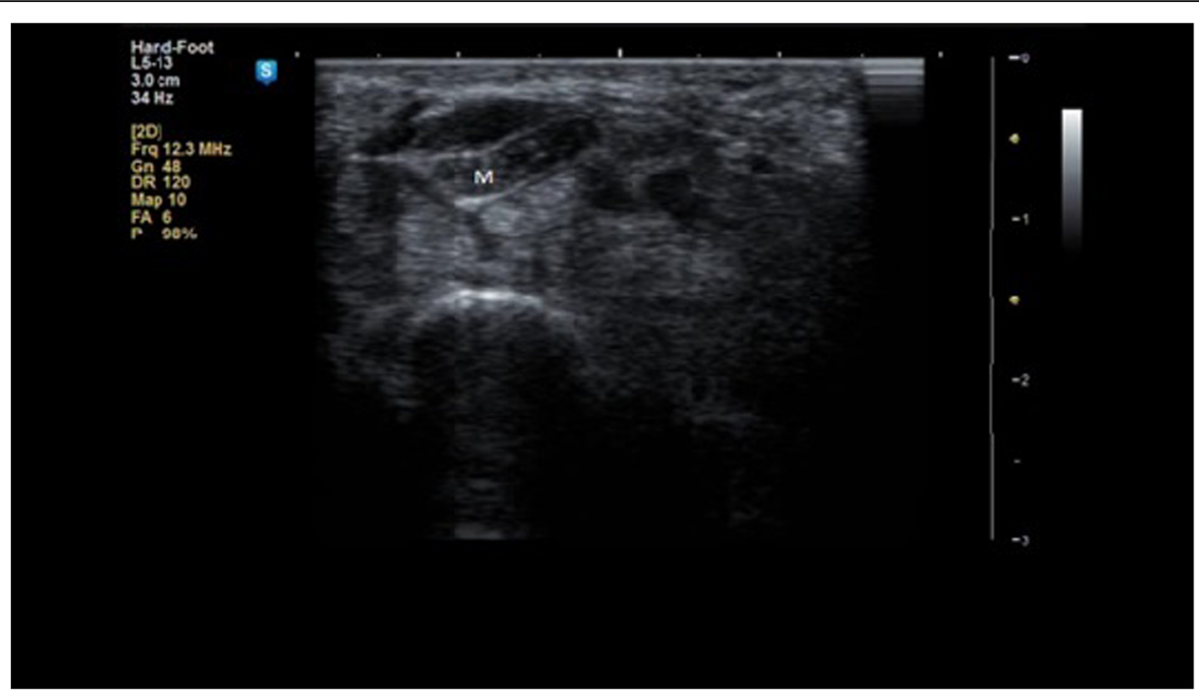

Fig. 1 The carpal tunnel was scanned to ensure that the PRP reached to the distal area of the carpal tunnel

- Electrophysiological parameters [24, 25]: antidromic $\mathrm{SNCV}$ and onset DML of the MN were measured in all patients by using Neuropack (USA) ${ }^{\circ}$ Wave electromyography device.

\section{Statistical analysis}

The collected data was analyzed using the SPSS software statistical computer package version 16. For quantitative data, the mean and standard deviation were calculated. For qualitative data, the number and percent distribution was calculated. Demographic statistics were analyzed using the independent $t$ test for continuous data and chi-square test for categorical data. The univariate ANOVA followed by post hoc power analysis was performed for the data at various follow-ups in both groups. The independent $t$ test was used to compare the differences between the groups. $p$ values $<0.05$ were considered statistically significant.

\section{Results}

All the forty patients completed the study, and twenty wrists in each study group were analyzed. The comparison between the two groups regarding clinical and

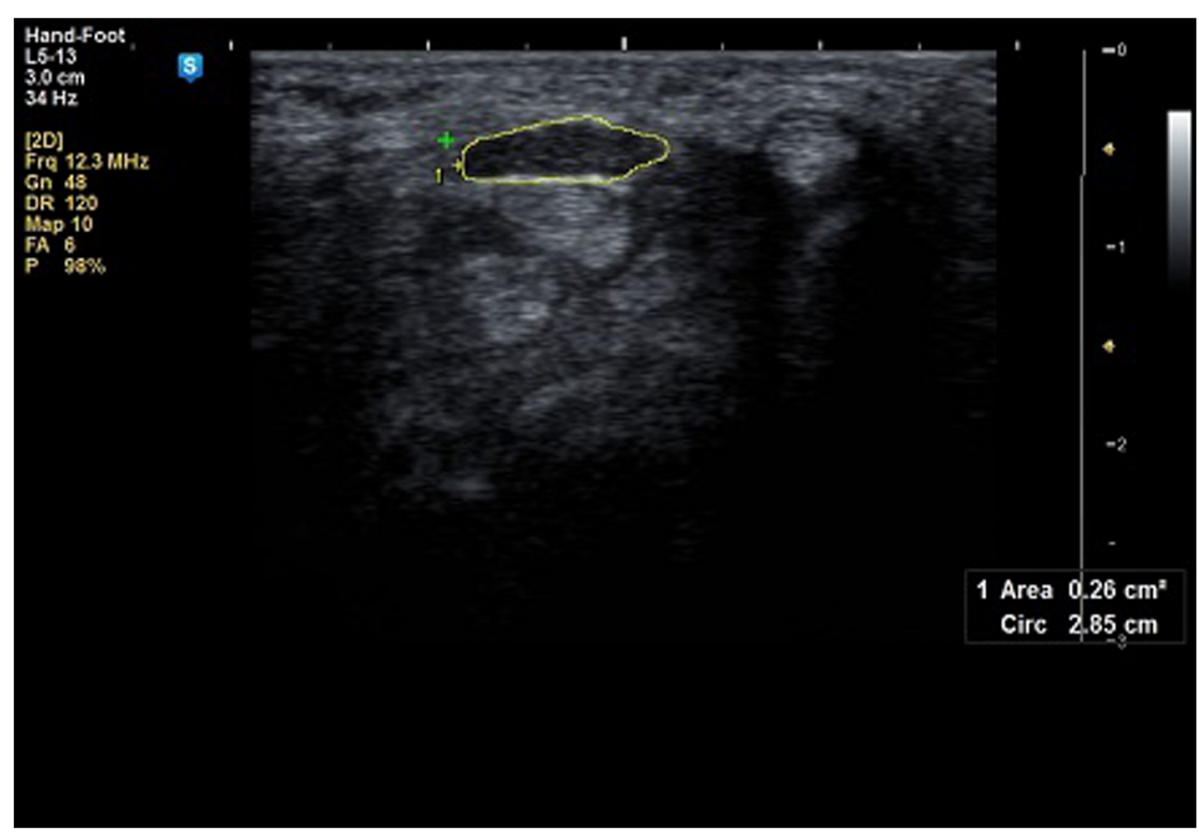

Fig. 2 CSA was measured at the proximal inlet of the carpal tunnel using the pisiform bone as a landmark 
demographic variables was found to be non-significantly different at the onset of the study (Table 1).

Comparing the baseline data of VAS scores, BCTQ scores, electrophysiological study, and cross-sectional area of the median nerve, a significant improvement in all tested outcome measures (except for the sensory nerve conduction velocity) was observed in the PRP and control groups respectively at all follow-up assessments (Table 2).

Finally comparing the differences in each variable between the two groups, there was significant improvement in the PRP group at follow-up assessments in the VAS scores. Significant improvement in the PRP group BCTQ scores and CSA of the MN was only noted at the third month follow-up assessment (Fig. 3). SNCV and DML outcome measures did not significantly differ between the two groups (Table 3).

\section{Discussion}

PRP in the treatment of CTS originated from the various experimental studies that had reported positive effects of PRP on regeneration of peripheral nerves without

Table 1 Comparison between the two groups regarding clinical and demographic variables

\begin{tabular}{|c|c|c|c|}
\hline & $\begin{array}{l}\text { PRP group } \\
(\boldsymbol{n}=20)\end{array}$ & $\begin{array}{l}\text { Control group } \\
(\boldsymbol{n}=20)\end{array}$ & $\boldsymbol{p}$ value \\
\hline Age & $46.93 \pm 4.41$ & $46.75 \pm 2.96$ & 0.884 \\
\hline Sex & & & 0.633 \\
\hline Male $(n)(\%)$ & $2(10)$ & $3(15)$ & \\
\hline Female $(n)(\%)$ & $18(90)$ & $17(85)$ & \\
\hline Duration (months) & $15.86 \pm 6.13$ & $14.90 \pm 6.70$ & 0.641 \\
\hline Diabetes mellitus (n) (\%) & $2(10)$ & $1(5)$ & 0.548 \\
\hline Dominant hand & & & 0.147 \\
\hline Right (n) (\%) & $20(100)$ & $18(90)$ & \\
\hline Left $(n)(\%)$ & $0(0)$ & $2(10)$ & \\
\hline Side of lesion & & & 0.519 \\
\hline Right (n) (\%) & $11(55)$ & $13(65)$ & \\
\hline Left $(n)(\%)$ & $9(45)$ & $7(35)$ & \\
\hline Severity & & & 0.288 \\
\hline Mild (n) (\%) & $16(80)$ & $13(65)$ & \\
\hline Moderate $(n)(\%)$ & $4(20)$ & $7(35)$ & \\
\hline VAS & $6.75 \pm 0.94$ & $6.47 \pm 0.70$ & 0.299 \\
\hline BCTQ-severity scale & $25.53 \pm 0.63$ & $25.27 \pm 0.73$ & 0.235 \\
\hline BCTQ-functional scale & $19.15 \pm 0.73$ & $18.83 \pm 0.69$ & 0.168 \\
\hline Median SNCV(m/s) & $32.83 \pm 3.50$ & $33.32 \pm 3.35$ & 0.653 \\
\hline Median DML (ms) & $4.97 \pm 0.32$ & $4.80 \pm 0.36$ & 0.112 \\
\hline $\operatorname{CSA}\left(\mathrm{mm}^{2}\right)$ & $13.62 \pm 0.64$ & $13.34 \pm 0.71$ & 0.196 \\
\hline
\end{tabular}

VAS visual analog scale, BCTQ Boston Carpal Tunnel Syndrome Questionnaire $S N C V$ sensory nerve conduction velocity, DML distal motor latency, CSA cross-sectional area
Table 2 Outcome measures in PRP and control groups before and after treatment

\begin{tabular}{|c|c|c|c|c|}
\hline & \multicolumn{2}{|c|}{ PRP group $(n=20)$} & \multicolumn{2}{|c|}{ Control $(n=20)$} \\
\hline & Mean \pm SE & $p$ value & Mean \pm SE & $p$ value \\
\hline VAS-Pre & $6.75 \pm 0.94$ & & $6.47 \pm 0.70$ & \\
\hline 1 & $4.38 \pm 0.94$ & $<0.001$ & $4.57 \pm 0.69$ & $<0.001$ \\
\hline 2 & $3.52 \pm 0.90$ & $<0.001$ & $4.06 \pm 0.65$ & $<0.001$ \\
\hline BCTQs-Pre & $25.53 \pm 0.63$ & & $25.27 \pm 0.73$ & \\
\hline 1 & $18.81 \pm 0.93$ & $<0.001$ & $18.57 \pm 1.14$ & $<0.001$ \\
\hline 3 & $17.50 \pm 0.90$ & $<0.001$ & $17.62 \pm 1.02$ & $<0.001$ \\
\hline BCTQf-Pre & $19.15 \pm 0.73$ & & $18.83 \pm 0.69$ & \\
\hline 1 & $13.94 \pm 0.66$ & $<0.001$ & $13.90 \pm 0.99$ & $<0.001$ \\
\hline 3 & $12.53 \pm 0.60$ & $<0.001$ & $13.03 \pm 1.12$ & $<0.001$ \\
\hline SNCV-Pre (m/s) & $32.83 \pm 3.50$ & & $33.32 \pm 3.35$ & \\
\hline 1 & $34.28 \pm 3.36$ & 0.365 & $34.85 \pm 3.34$ & 0.323 \\
\hline 3 & $34.73 \pm 3.23$ & 0.182 & $35.32 \pm 3.32$ & 0.149 \\
\hline DML-Pre (ms) & $4.97 \pm 0.32$ & & $4.80 \pm 0.36$ & \\
\hline 1 & $4.71 \pm 0.32$ & 0.028 & $4.54 \pm 0.35$ & 0.050 \\
\hline 3 & $4.67 \pm 0.31$ & 0.012 & $4.52 \pm 0.34$ & 0.033 \\
\hline CSA-Pre $\left(\mathrm{mm}^{2}\right)$ & $13.60 \pm 0.67$ & & $13.34 \pm 0.71$ & \\
\hline 1 & $12.03 \pm 0.94$ & 0.020 & $12.32 \pm 0.84$ & 0.047 \\
\hline 3 & $11.60 \pm 0.93$ & $<0.001$ & $12.08 \pm 0.81$ & $<0.001$ \\
\hline
\end{tabular}

VAS visual analog scale, BCTQ Boston Carpal Tunnel Syndrome Questionnaire, $S N C V$ sensory nerve conduction velocity, DML distal motor latency, CSA crosssectional area, Pre pretreatment

considerable risks [26]. Other studies revealed a significant effect of PRP on functional axon recovery as PRP could stimulate Schwann cell proliferation, secretion of nerve growth factor, and neurotrophic factor in vitro [27].

Farrag et al. and Cho et al. [28, 29] demonstrated beneficial effects of PRP for facial nerve regeneration in a rat model. Sariguney et al. and Giannessi et al. [30, 31] showed that PRP enhanced the remyelination and axonal regeneration of the sciatic nerve. In contrast, Piskin et al. [32] reported that PRP does not enhance axonal regeneration of peripheral nerve repair in a rat model.

In this study, PRP injection significantly improved the pain, disease severity, and functional disabilities of CTS and cross-sectional area and the distal motor latencies of the median nerve; also, there was a significant improvement in all outcome variables in the control group. There was no significant improvement in the sensory nerve conduction velocity in both PRP and control groups ( $p=0.182$ and 0.149 respectively) (Table 2 ).

In agreement with our results, Raeissadat et al. [33] performed a randomized controlled trial to evaluate PRP safety in women with CTS ( $n=20$ vs. $n=21$ ) using single blind PRP injection; they reported significant improvements in pain and symptom severity and 

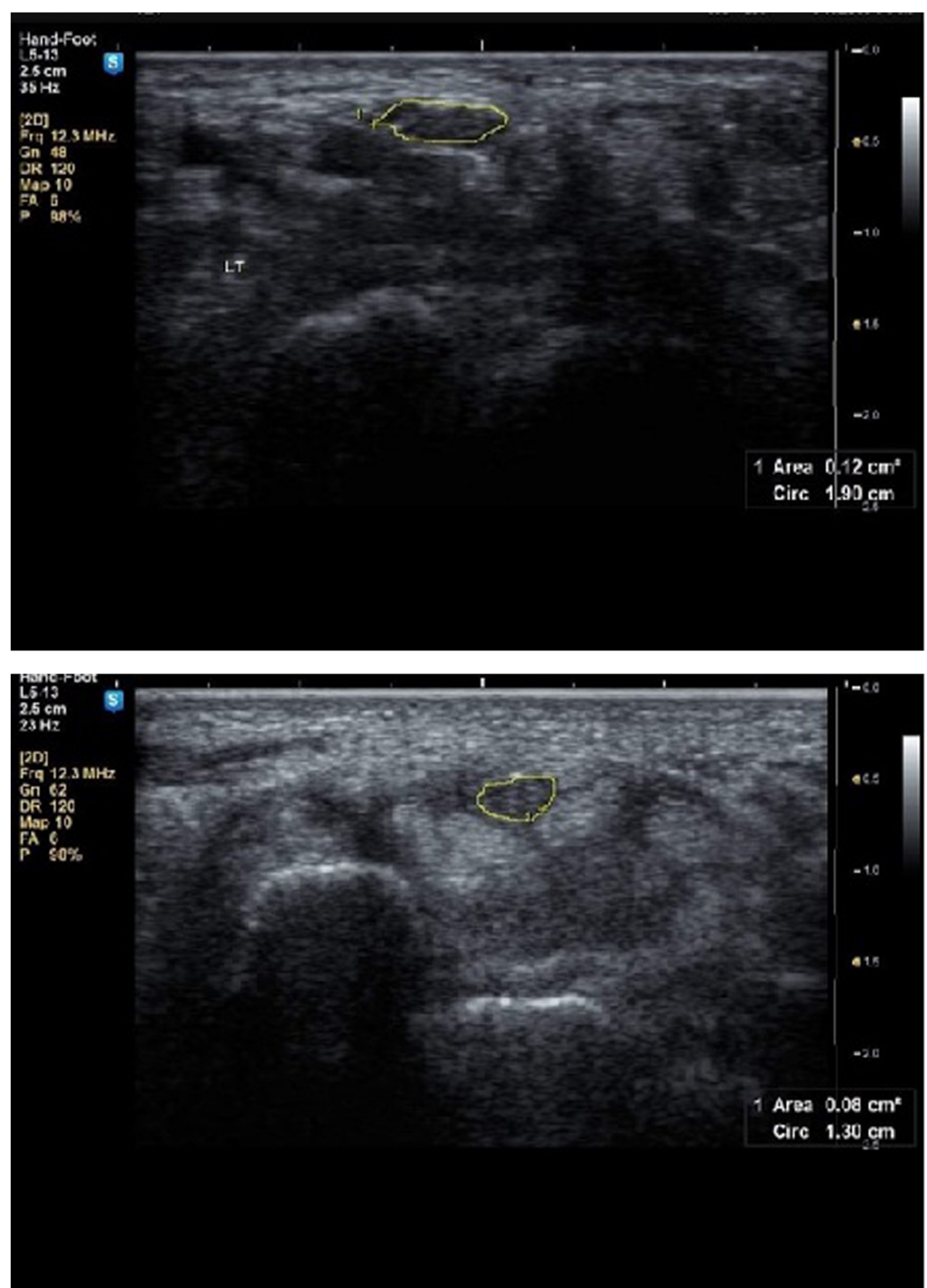

Fig. 3 Significant improvement in CSA of the MN in the PRP group was only noticed at third month follow-up assessment

functional status of patients, assessed according to the VAS and BCTQ and also electrophysiological parameters, in both PRP and splint groups, after 10 weeks of treatment except for the median CMAP onset latency in the PRP group. $(p=0.472)$.

Also, Wu et al. [34] conducted a prospective randomized, single-blind controlled trial to study the 6-month efficacy of platelet-rich plasma for mild and moderate carpal tunnel syndrome ( $n=30$ vs. $n=30$ ); when comparing the VAS scores, BCTQ scores, electrophysiological study, CSA of the median nerve, and finger pinch baseline, with post-treatment data, a significant improvement in all outcome measures was observed in the PRP and control groups at all follow-up assessments $(p<0.05)$.

Uzun et al. [35] performed a non-randomized, singleblind trial to compare the effect of PRP with steroid injection in patients with minimal to mild CTS ( $n=20$ vs. $n=20$ ) by using blind injection. They recorded improvements in sensory nerve conduction after 3 months in both groups, although distal motor latencies did not change in either of the groups during the follow-up period. 
Table 3 Comparison of outcome measures differences between baseline and follow-up assessments in the PRP and control groups

\begin{tabular}{|c|c|c|c|c|c|}
\hline & \multirow{2}{*}{$\begin{array}{l}\text { PRP group }(\boldsymbol{n}=20) \\
\text { Mean difference } \pm \text { SD }\end{array}$} & \multirow{2}{*}{$\begin{array}{l}\text { Control }(\boldsymbol{n}=20) \\
\text { Mean difference } \pm \text { SD }\end{array}$} & \multirow[t]{2}{*}{$\boldsymbol{p}$ value } & \multicolumn{2}{|l|}{ Cl 95\% } \\
\hline & & & & Upper & Lower \\
\hline \multicolumn{6}{|l|}{ VAS-Pre } \\
\hline VAS-1 month & $-2.37 \pm 0.16$ & $-1.90 \pm 0.17$ & $<0.001$ & 0.34 & -0.73 \\
\hline VAS-3 month & $-0.86 \pm 0.21$ & $-0.52 \pm 0.12$ & $<0.001$ & -0.03 & -1.05 \\
\hline \multicolumn{6}{|l|}{ BCTQs-Pre } \\
\hline BCTQs-1 month & $-6.72 \pm 0.77$ & $-6.70 \pm 0.95$ & 0.957 & 0.91 & -4.28 \\
\hline BCTQs-3 month & $-1.31 \pm 0.48$ & $-0.96 \pm 0.38$ & 0.015 & 0.50 & -0.73 \\
\hline \multicolumn{6}{|l|}{ BCTQf-Pre } \\
\hline BCTQf-1 month & $-5.21 \pm 0.40$ & $-4.93 \pm 0.60$ & 0.098 & 0.58 & -0.50 \\
\hline BCTQf-3 month & $-1.42 \pm 0.30$ & $-0.88 \pm 0.36$ & $<0.001$ & 0.08 & -1.08 \\
\hline \multicolumn{6}{|l|}{ SNCV-Pre (m/s) } \\
\hline SNCV-1 month & $1.46 \pm 0.43$ & $1.53 \pm 0.38$ & 0.562 & 1.6 & -2.71 \\
\hline SNCV-3 month & $0.45 \pm 0.34$ & $0.47 \pm 0.30$ & 0.845 & 1.51 & -2.68 \\
\hline \multicolumn{6}{|l|}{ DML-Pre (ms) } \\
\hline DML-1 month & $-0.27 \pm 0.07$ & $-0.25 \pm 0.05$ & 0.530 & 0.38 & -0.05 \\
\hline DML-3 month & $-0.03 \pm 0.04$ & $-0.02 \pm 0.02$ & 0.534 & 0.36 & -0.05 \\
\hline \multicolumn{6}{|l|}{ CSA-Pre $\left(\mathrm{mm}^{2}\right)$} \\
\hline CSA-1 month & $-0.66 \pm 0.32$ & $-0.53 \pm 0.28$ & 0.195 & 0.60 & -0.25 \\
\hline CSA-3 month & $-1.40 \pm 0.57$ & $-0.91 \pm 0.45$ & 0.004 & 0.26 & -0.92 \\
\hline
\end{tabular}

VAS visual analog scale, BCTQ Boston Carpal Tunnel Syndrome Questionnaire, SNCV sensory nerve conduction velocity, DML distal motor latency, CSA crosssectional area, Pre pretreatment, $S D$ standard deviation

In 2015, Malahias et al. [36] first used an ultrasoundguided injection of $1-2 \mathrm{~mL}$ of PRP in patients with mild CTS ( $n=14$, no control group) with positive mid-term outcomes (3 months). Sánchez et al. [26] described a patient with recalcitrant peroneal nerve palsy who showed partial recovery and obvious improvement in the electrophysiological study 21 months after the first PRP injection (7 sessions of PRP injection in total). Anjayani et al. [10] reported a randomized, double-blind, control trial study to prove that a 1-mL PRP perineural injection could improve pain scores using a VAS, and the twopoint discrimination test of peripheral neuropathy, in patients with Hansen's disease compared with a 1-mL PPP injection, 2 weeks after the injection of both types of plasma ( $n=30$ vs. $n=30$, respectively).

In our study, while comparing the differences in outcome variables of both PRP and control groups, there was significant improvement in the PRP group at the 1st and 3rd month VAS scores, the 3rd month BCTQseverity and functional scores, and CSA of the MN. The difference in SNCV and DML between the two groups was not statistically significant (Table 3 ).

Similar to our results, Wu et al. [34] found that, comparing the PRP and control groups, there was a significantly greater enhancement in the PRP group at all follow-up time points in the VAS scores, BCTQ scores, and CSA of the MN (except for the 1st and 3rd month
VAS score and 1st month BCTQ-severity score), and this tendency became more pronounced as the followup duration increased. The difference in SNCV and DML between the two groups was not statistically significant at all follow-up assessments. It is therefore possible that PRP may exhibit a delayed effect.

Uzun et al. [35] showed that the PRP group had a significant improvement of BCTQ (both symptom and function scores) 3 months post-treatment compared with the steroid group, but the difference was not significant at the 6 month follow-up. Moreover, there was no significant change between the two groups in the electrophysiological measurements, so they considered PRP only as a temporary symptomatic relief for mild carpal tunnel syndrome

In contrast to our results, Raeissadat et al. [33] found that the changes in the evaluated outcome measures between the PRP and control groups of patients were not statistically significant even when the analyses were adjusted for age of the patients, and the PRP injection did not add considerably to the effects of wrist splint.

Several mechanisms were postulated to explain the effect of PRP on CTS relief: PRP could promote angiogenesis, neurogenesis, and regeneration via direct effects on the median nerve, PRP could reduce the flexors tenosynovitis, which would result in reduction of intracarpal pressure exerted on the median nerve, and finally, the hydrodissection could have some benefits [36-39]. 


\section{Conclusion}

Ultrasound-guided PRP injection is recommended for safe, effective symptomatic relief of mild and moderate carpal tunnel syndrome. More ongoing researches on PRP effects on peripheral neuropathy and CTS with longer follow-up periods are recommended to evaluate the exact mechanism of PRP, to determine its dosage regimen for best efficacy, and to investigate whether it is a long-lasting therapeutic approach or it is merely a temporary relief.

\section{Abbreviations}

CTS: Carpal tunnel syndrome; CSA: Cross-sectional area; DML: Distal motor latency; D5W: 5\% dextrose in water; MN: Median nerve; PRP: Platelet rich plasma; SNCV: Sensory nerve conduction velocity; BCTQ: The Boston Carpal Tunnel Syndrome Questionnaire; VAS: Visual analog scale

\section{Acknowledgements}

Many thanks for Prof. Dr. Radwa EL-Khouly, EULAR certified rheumatologist, who performed the MSUS.

\section{Authors' contributions}

SG performed the clinical examination and electro-diagnosis. HE analyzed and interpreted the patient's data; we performed the PRP injection. All authors read and approved the final manuscript.

\section{Funding}

This research did not receive any specific grant from funding agencies.

\section{Availability of data and materials}

Not applicable

\section{Ethics approval and consent to participate}

The study was approved by the local Ethics Committee of Faculty of Medicine, Tanta University. Approval Code 40256/12/18. The written informed consent from all the patients was obtained, and the trial was conducted according to the Declaration of Helsinki principles.

\section{Consent for publication}

Not applicable.

\section{Competing interests}

We declare no conflicts of interest.

Received: 26 March 2020 Accepted: 18 May 2020

Published online: 03 August 2020

\section{References}

1. Ghasemi-rad M, Nosair E, Vegh A, Mohammadi A, Akkad A, Lesha E (2014) A handy review of carpal tunnel syndrome: from anatomy to diagnosis and treatment. World J Radiol 6(6):284

2. Ibrahim SE, Hussein A (2016) New role for insulin injection in the treatment of idiopathic carpal tunnel syndrome. J Egypt rheumatol Rehabil 43:157-162

3. Dinarvand V, Abdollahi I, Raeissadat SA, Mohseni Bandpei MA, Babaee M, Talimkhani A (2017) The effect of scaphoid and hamate mobilization on treatment of patients with carpal tunnel syndrome. Anesthesiol Pain Med 7(5):e14621

4. Bahrami MH, Shahraeeni S, Raeissadat SA (2015) Comparison between the effects of progesterone versus corticosteroid local injections in mild and moderate carpal tunnel syndrome: a randomized clinical trial. BMC Musculoskelet Disord 16:322

5. Ahčan U, Arnez ZM, Bajrović F, Zorman P (2002) Surgical technique to reduce scar discomfort after carpal tunnel surgery. J Hand Surg Am 27(5): $821-827$

6. Raeissadat A, Reza Soltani Z (2011) Study of long term effects of laser therapy versus local corticosteroid injection in patients with carpal tunnel syndrome. J Lasers Med Sci 1(1):7
7. Huisstede BM, Hoogvliet P, Randsdorp MS, Glerum S, van Middelkoop M, Koes BW (2010) Carpal tunnel syndrome. Part l: effectiveness of nonsurgical treatments-a systematic review. Arch Phys Med Rehabil 91(7):981-1004

8. Sundman EA, Cole BJ, Fortier LA (2011) Growth factor and catabolic cytokine concentrations are influenced by the cellular composition of platelet-rich plasma. Am J Sports Med 39(10):2135-2140

9. Raeissadat SA, Babaee M, Rayegani SM, Hashemi Z, Hamidieh AA, Mojgani P (2017) An overview of platelet products (PRP, PRGF, PRF, etc.) in the Iranian studies. Future Sci OA 3 (4):Fso231.

10. Anjayani S, Wirohadidjojo YW, Adam AM, Suwandi D, Seweng A, Amiruddin M (2014) Sensory improvement of leprosy peripheral neuropathy in patients treated with perineural injection of platelet-rich plasma. Int J Dermatol 53(1):109-113

11. Sanchez M, Yoshioka T, Ortega M, Delgado D, Anitua E (2014) Ultrasoundguided platelet-rich plasma injections for the treatment of common peroneal nerve palsy associated with multiple ligament injuries of the knee. Knee Surg Sports Traumatol Arthrosc 22(5):1084-1089

12. Rose L. F, Wolf EJ, Brindle T, Cernich A, Dean WK, Dearth CL, Grimm M, Kusiak A, Nitkin R., Potter K (2018) The convergence of regenerative medicine and rehabilitation: federal perspectives. NPJ Regen. Med 3, 19.

13. Mishra A, Woodall J, Vieira A (2009). Treatment of tendon and muscle using platelet-rich plasma. Clin. Sports Med28, 113-125.

14. Hauser RA, Lackner JB, Steilen-Matias D, Harris DK (2016) A systematic review of dextrose prolotherapy for chronic musculoskeletal pain. Clin. Med. Insights Arthritis Musculoskelet. Disord 9:139-159

15. Evers S, Thoreson AR, Smith J, Zhao C, Geske JR, Amadio PC (2018) Ultrasound-guided hydrodissection decreases gliding resistance of the median nerve within the carpal tunnel. Muscle Nerve 57:25-32

16. Wu YT, Chen SR, Li TY, Ho TY, Shen YP, Tsai CK, Chen LC (2019) Nerve hydrodissection for carpal tunnel syndrome: a prospective, randomized, double-blind, controlled trial. Muscle Nerve 59:174-180

17. Padua L, LoMonaco M, Gregori B, Valente EM, Padua R, Tonali P (1997) Neurophysiological classification and sensitivity in 500 carpal tunnel syndrome hands. Acta Neurol Scand 96:211-217

18. Zhu Y, Yuan M, Meng H, Wang A, Guo Q, Wang Y (2013) Basic science and clinical application of platelet-rich plasma for cartilage defects and osteoarthritis: a review. Osteoarthr Cartil 21(11):1627-1637

19. Ettema AM, Amadio PC, Zhao C, Wold LE, An KN (2004) A histological and immunohistochemical study of the subsynovial connective tissue in idiopathic carpal tunnel syndrome. J. Bone Joint Surg. Am 86:1458-1466

20. Wong SM, Griffith JF, Hui AC, Tang A, Wong KS (2002) Discriminatory sonographic criteria for the diagnosis of carpal tunnel syndrome. Arthritis Rheum 46:1914-1921

21. Lee JY, Park Y, Park KD, Lee JK, Lim OK (2014) Effectiveness of ultrasoundguided carpal tunnel injection using in-plane ulnar approach: a prospective, randomized, single-blinded study. Medicine 93:e350

22. Huskisson EC (1974) Measurement of pain. Lancet 2:1127-1131

23. Levine DW, Simmons BP, Koris MJ, Daltroy LH, Hohl GG, Fossel AH (1993) A self-administered questionnaire for the assessment of severity of symptoms and functional status in carpal tunnel syndrome. J Bone Joint Surg Am 75: $1585-1592$

24. Wu YT, Ke MJ, Chou YC, Chang CY, Lin CY, Li TY (2016) Effect of radial shock wave therapy for carpal tunnel syndrome: a prospective randomized, double-blind, placebo-controlled trial. J Orthop Res 34:977-984

25. Jablecki CK, Andary MT, So YT, Wilkins DE, Williams FH (1993) Literature review of the usefulness of nerve conduction studies and electromyography for the evaluation of patients with carpal tunnel syndrome. Aaem quality assurance committee. Muscle \& nerve 16:1392-1414

26. Sánchez M, Anitua E, Delgado D, Prado R, Sánchez P, Fiz N (2017) Ultrasound-guided plasma rich in growth factors injections and scaffolds hasten motor nerve functional recovery in an ovine model of nerve crush injury. J Tissue Eng Regen Med 11(5):1619-1629

27. Zheng C, Zhu Q, Liu X, Huang X, He C, Jiang L (2016) Effect of platelet-rich plasma (PRP) concentration on proliferation, neurotrophic function and migration of Schwann cells in vitro. J Tissue Eng Regen Med 10(5):428-436

28. Farrag TY, Lehar M, Verhaegen P, Carson KA, Byrne PJ (2007) Effect of platelet rich plasma and fibrin sealant on facial nerve regeneration in a rat model. Laryngoscope 117(1):157-165

29. Cho HH, Jang S, Lee SC, Jeong HS, Park JS, Han JY (2010) Effect of neuralinduced mesenchymal stem cells and platelet-rich plasma on facial nerve regeneration in an acute nerve injury model. Laryngoscope 120(5):907-913 
30. Sariguney Y, Yavuzer R, Elmas C, Yenicesu I, Bolay H, Atabay K (2008) Effect of platelet-rich plasma on peripheral nerve regeneration. J Reconstr Microsurg. 24(03):159-167

31. Giannessi E, Coli A, Stornelli MR, Miragliotta V, Pirone A, Lenzi C (2014) An autologously generated platelet-rich plasma suturable membrane may enhance peripheral nerve regeneration after neurorraphy in an acute injury model of sciatic nerve neurotmesis. J Reconstr Microsurg 30(09):617-626

32. Piskin A, Kaplan S, Ayyildiz M, Raimondo S, Bozkurt HH, Geuna S (2009) Platelet gel does not improve peripheral nerve regeneration: an electrophysiological, stereological, and electron microscopic study. Microsurgery 29(2):144-153

33. Raeissadat SA, Karimzadeh A, Hashemi M, Bagherzadeh L (2018) Safety and efficacy of platelet-rich plasma in treatment of carpal tunnel syndrome; a randomized controlled trial. BMC Musculoskelet Disord 19: 49.

34. Wu YT, Ho TY, Chou YC, Ke MJ, Li TY, Huang GS (2017) Six-month efficacy of platelet-rich plasma for carpal tunnel syndrome: a prospective randomized, single-blind controlled trial. Sci Rep 7:1

35. Uzun H, Bitik O, Uzun Ö, Ersoy US, Aktaş E (2017) Platelet-rich plasma versus corticosteroid injections for carpal tunnel syndrome. J Plast Surg Hand Surg 51(5):301-305

36. Malahias MA, Johnson EO, Babis GC, Nikolaou VS (2015) Single injection of platelet-rich plasma as a novel treatment of carpal tunnel syndrome. Neural Regen Res 10(11):1856

37. Takamura M, Yasuda T, Nakano A, Shima H, Neo M (2017) The effect of platelet-rich plasma on Achilles tendon healing in a rabbit model. Acta Orthop Traumatol Turc 51(1):65-72

38. Ding XG, Li SW, Zheng XM, Hu LQ, Hu WL, Luo Y (2009) The effect of platelet-rich plasma on cavernous nerve regeneration in a rat model. Asian J Androl 11(2):215

39. Park GY, Kwon DR (2014) Platelet-rich plasma limits the nerve injury caused by $10 \%$ dextrose in the rabbit median nerve. Muscle Nerve 49(1):56-60

\section{Publisher's Note}

Springer Nature remains neutral with regard to jurisdictional claims in published maps and institutional affiliations.

\section{Submit your manuscript to a SpringerOpen ${ }^{\circ}$ journal and benefit from:}

- Convenient online submission

- Rigorous peer review

- Open access: articles freely available online

High visibility within the field

- Retaining the copyright to your article

Submit your next manuscript at $\boldsymbol{\nabla}$ springeropen.com 